J. Lake Sci.(湖泊科学), 2008, 20(3): 364-368

http://www.jlakes.org. E-mail: jlakes@niglas.ac.cn

(C)2008 by Journal of Lake Sciences

\title{
近年来黄河源头地区玛多县湖泊变化 ${ }^{*}$
}

\author{
吴素霞 ${ }^{1}$, 常国刚 ${ }^{2}$, 李凤霞 ${ }^{1}$, 肖建设 ${ }^{1}$, 郭安红 ${ }^{3}$ \\ (1: 青海省气象科学研究所, 西宁 810001) \\ (2: 青海省气象局, 西宁 810001) \\ (3: 中国气象科学研究院, 北京 100081)
}

摘 要: 根据时间序列数据 2001-2006 年连续 6 年的 MODIS 资料, 连续监测了玛多县近几年的湖泊变化情况, 结果表明玛多全 县 2006 年的湖泊比 2001 年多 35 个, 湖泊面积增加了 $56.59 \mathrm{~km}^{2}$, 以 2003 年为最低值, 从 2001-2003 年全县湖泊面积逐年减少, 而 从 2003-2006 年全县湖泊面积逐年增加. 各主要湖泊呈现不同的变化趋势, 与全县湖泊的变化趋势不太一致. 年降水量与全县湖 泊面积相关系数最大, 说明年降水量对全县湖泊面积的影响较大, 各主要湖泊受各气候要素的影响大小也不一样.

关键词: 玛多县; 湖泊变化; MODIS; 黄河源区

\section{Recent lake changes in Maduo County, source region of the Yellow River}

\author{
WU Suxia ${ }^{1}$, CHANG Guogang ${ }^{2}$, LI Fengxia ${ }^{1}$, XIAO Jianshe ${ }^{1} \&$ GUO Anhong ${ }^{3}$ \\ (1: Qinghai Institute of Meteorological Science, Xining 810001, P.R.China) \\ (2: Meteorological Bureau of Qinghai Province, Xining 810001, P.R.China) \\ (3: Chinese Academy of Meteorological Sciences, Beijing 100081, P.R.China)
}

Abstract: Based on the continuous six-year MODIS data (from 2001 to 2006), changes of lakes in Maduo County were continuously monitored in recent years. The results showed that there were 35 lakes in 2006 more than that in 2001, and the lakes' area in 2006 was $56.59 \mathrm{~km}^{2}$ larger than that in 2001. The lake numbers and areas kept decreasing from 2001 to 2003 and were the least in 2003 , but yearly increased from 2003 to 2006. Each lake presented the different change tendency, and was not consistent with general trend of lake changes of the county. The correlation coefficient between annual precipitation and the lakes' area was the most significant which indicated that the annual precipitation had important effect on the lakes' area of the county. Climatic elements had different effects on main lakes.

Keywords: Maduo County; lake change; MODIS; source region of the Yellow River

黄河发源于巴颜喀拉山北麓，青海省境内全长 $1959 \mathrm{~km}$ ，占干流全长 $5464 \mathrm{~km}$ 的 $36 \%$ ，主要支流有多曲、 热曲等，年平均径流量 $232 \times 10^{8} \mathrm{~m}^{3}$ ，占整个黄河流域水资源总量的 $49 \%$. 玛多县是 “万里黄河第一县” ，是 黄河源头最大的水源涵养区，但随着源区人为活动增多，气候变暖，冰川、雪山逐年退缩，湖泊、湿地面积 逐年缩小，水位不断下降，草原沙漠化日趋严重，植被与湿地生态系统破坏，水源涵养能力急剧减退，黄河 源头多次出现断流 ${ }^{[1]}$. 这不仅影响了当地社会经济的发展，而且也危及到中下游地区社会经济的健康发展 和人民生产、生活的安全. 有关黄河源区的湖泊变化遥感监测已有很多研究报道 ${ }^{[1-4]}$, 但是以往这些研究, 由于受遥感资料的限制，通常都是利用较长时间序列中的几个时相的资料来代表整个阶段的变化，这不仅 难以反映湖泊的连续性变化特征, 而且对于湖泊动态变化对气候变化的响应也难以定量分析. 为此, 本研 究基于 MODIS 资料, 提取了黄河源区－玛多县湖泊从 2001-2006 年连续 6 年时间序列信息, 分析了近年来黄 河源区湖泊的连续动态变化情况, 为进一步研究黄河源区湖泊变化对气候变化的敏感性研究提供了基础数据.

* 国家自然科学基金项目(40405022)、科研院所社会公益研究专项(2005DIB3J109)和干早气象科学研究基金(IAM200708)联合 资助. 2007-04-02 收稿; 2007-08-25 收修改稿. 吴素霞, 女, 1978 年生; E-mail: suxiawu@163.com. 


\section{1 研究区概况}

玛多县位于青海省果洛藏族自治州西北部, 县府驻玛查里(黑河乡境内), 距西宁市 $497 \mathrm{~km}$. 地处黄河 源头, 巴颜喀拉山北麓, 阿尼玛卿雪山以西的黄河谷地, 地理位置为北纬 $34^{\circ} 00^{\prime}-35^{\circ} 40^{\prime}$, 东经 $96^{\circ} 50^{\prime}-99^{\circ} 20^{\prime}$, 面积约 $2.5 \times 10^{4} \mathrm{~km}^{2}$, 大部分地区海拔高度在 $4200 \mathrm{~m}$ 以上. 全县以牧业为主，可利用草场 面积 $14350 \mathrm{~km}^{2}$, 野生动物有野牛、野驴、黄羊和白唇鹿等. 境内山峦起伏, 河流纵横, 大小湖泊星罗棋布. 著名的扎陵湖、鄂陵湖就在境内, 素有 “千湖之县” 的称号. 玛多县地势高立, 空气稀薄, 气候寒冷, 四 季不分明, 没有绝对的无霜期. 属高原大陆性半湿润气候, 年平均气温 -5.3 至 $-2.4^{\circ} \mathrm{C}$, 多年平均降水量 $312.8 \mathrm{~mm}$ 左右, 年蒸发量为 $1333.9 \mathrm{~mm}$, 最大风速可达 $26 \mathrm{~m} / \mathrm{s}$.

\section{2 数据的收集与预处理}

\section{1 数据的收集}

EOS(Earth Observing System)是美国新一代的地球观测系统，其中装载的中分辨率成像光谱仪 (MODIS), 它具有观测从太阳短波到热红外, 光谱范围从 0.4-14.5 $\mu \mathrm{m}$ 的 36 个光谱波段, 能反映陆地、云 边界、云特征、海洋水色、浮游植物、生物地理、化学、大气中水汽、地表温度、云顶温度、大气温度、 臭氧等特征信息. 扫描宽度为 $2330 \mathrm{~km}$ ，地面分辨率为 $250 \mathrm{~m} 、 500 \mathrm{~m} 、 1000 \mathrm{~m}$ ，运行周期为 $1-2 \mathrm{~d}$ ，每天或每 两天可以获取一次全球观测数据 ${ }^{[5]}$. 因此本研究选取 MODIS 数据作为数据源.

考虑到在 5 月份和 9 月份玛多县的湖泊面积相对稳定, 所以本研究中所用的资料为该县 2001-2006 年 5 月份(准 5 月份)和 9 月份(准 9 月份)的 MODIS 晴空资料. 资料主要来源于青海省遥感中心和美国 NASA 网站.

\section{2 数据的预处理}

对收集到的 12 个时相的 MODIS 数据, 首先利用星地通公司 EOS/MODIS 后端处理系统, 进行数据 定标、辐射校正、几何校正、投影变换等, 本研究采用的是 ALBERS 等面积投影, 椭球体为 WGS84. 在 ENVI 软件的支持下进行各个时相数据的配准, 配准误差控制在半个像元之内, 叠加玛多县的行政边界, 切割出研究区域以备后用.

\section{3 湖泊提取的原理与方法}

\section{1 水体监测原理}

卫星遥感图像真实地记载了地物自身的热辐射和对太阳辐射的反射信息，由于各种物体的组成成 分、物理和化学特性差异导致电磁波谱特征各不相同. 在可见光通道 1 地面水体的反射率总体上比较低, 不超过 $10 \%$, 并随波长的增大而逐渐降低, 到 $0.6 \mu \mathrm{m}$ 处约为 $2 \%-3 \%$, 过了 $0.75 \mu \mathrm{m}$ 水体几乎为全吸收 ${ }^{[6]}$, 因此, 在近红外的遥感影像上, 清澈的水体呈黑色. 而土壤和植被却恰好相反，在近红外和中红外波段 的电磁波被强烈的反射(尤其在近红外波段), 这与水体形成了鲜明的对照, 所以水体在近红外波段上与 土壤和植被有明显的区别.

\section{2 水体信息提取方法}

MODIS 数据水体信息的提取方法主要有 2 种 $^{[7]}$ : 其一, 为提取资料中所含水体信息, 首先需生成多 光谱合成彩色图像，对目标作人工判识; 其二，通过用单通道灰度值法提取水体信息，利用阈值法能够 提取出水体信息. 本研究基于水体与陆地 (土壤、植被)在通道 1 和通道 2 的光谱信息特点, 采用通道 2 与 通道 1 之比扩大它们的信息差异, 利用简单的阈值法来提取水体, 低于此阈值的地物被认为是水体. 为 了提高监测的精度，对于不同的时相采用不同的阈值.

模型: $\mathrm{Ch} 2 / \mathrm{Ch} 1<\mathrm{Th} 1 \& \mathrm{Ch} 2<\mathrm{Th} 2$

满足上式条件的为水体. 其中, Ch1、Ch2 为 MODIS 第 $1 、 2$ 通道的反射率, Th1、Th2 为阈值.

\section{3 湖泊面积、个数等参数的提取}

对在 ENVI 软件下生成的水体图, 利用栅格转矢量的工具得到水体的矢量图, 根据在该地区以往的 研究结果, 剔除河流和水库, 剩下的水体即为湖泊, 在 ARCVIEW 中统计各时相湖泊的面积、斑块数、周 长等. 由于本研究中根据 $1 、 2$ 通道的光谱特征进行水体信息的提取, 分辨率为 $250 \mathrm{~m}$, 为此本研究中提取 
的水体面积 $\geqslant 0.0625 \mathrm{~km}^{2}$.

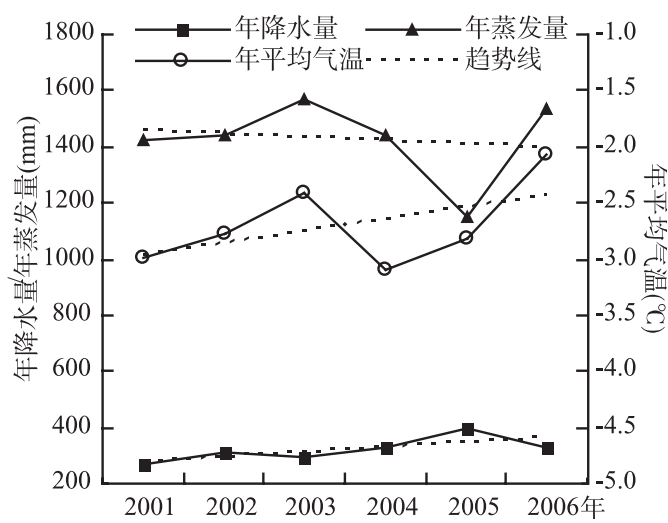

图 1 玛多县年降水量、年蒸发量、年平均 气温年际变化曲线和趋势线

Fig.1 Interannual variation and trend lines of annual precipitation, annual evaporation and annual mean temperature in Maduo County

\section{4 结果分析}

\section{1 近年来玛多县气候变化概况}

从玛多全县的气候要素年际变化曲线(图 1)可 以看出, 玛多县的气温升高、降水增加, 气候出现 了暖湿化的特征. 从 2001-2006 年全县的年平均气 温呈明显上升趋势, 仅隔 5 年年平均气温升高了 $0.9^{\circ} \mathrm{C}$, 平均每年升温 $0.18^{\circ} \mathrm{C}$, 年降水量呈现平稳上 升的趋势, 而年蒸发量波动比较大, 总体上表现为 下降趋势, 但下降趋势不明显. 就玛多县 2001-2006 年四季(表 1)来讲, 气温除年际出现波动 (以秋季波动最大)外, 总体上四季气温呈现上升趋 势, 以冬季的增温最为明显. 四季的降水量变化趋 势不一致, 除夏季的降水有增加外, 其他季节降水 量都有不同程度的减少. 春季和冬季蒸发上升, 夏 季和秋季蒸发有所下降.

表 1 近年来玛多县四季降水、蒸发、气温变化

Tab.1 In recent years the changes of precipitation, evaporation and temperature in different season in Maduo County

\begin{tabular}{clllllll}
\hline 气候要素 & 季节 & 2001 年 & 2002 年 & 2003 年 & 2004 年 & 2005 年 & 2006 年 \\
\hline 降水量 & 春 & 45.0 & 48.0 & 48.4 & 83.0 & 69.4 & 30.2 \\
$(\mathrm{~mm})$ & 夏 & 133.6 & 178.5 & 207.5 & 149.5 & 232.4 & 225.8 \\
& 秋 & 74.7 & 79.2 & 35.1 & 92.7 & 81.0 & 60.8 \\
& 冬 & 11.8 & 9.3 & 2.8 & 9.1 & 12.2 & 7.0 \\
蒸发量 & 春 & 378.8 & 413.3 & 451.1 & 444.4 & 396.2 & 410.4 \\
$(\mathrm{~mm})$ & 夏 & 595.2 & 543.8 & 554.0 & 553.2 & 357.6 & 657.6 \\
& 秋 & 285.3 & 290.9 & 361.8 & 281.6 & 228.1 & 276.4 \\
& 冬 & 174.8 & 172.3 & 204.1 & 173.9 & 161.4 & 203.2 \\
气温 & 春 & -4.1 & -2.8 & -2.2 & -2.3 & -3.1 & -3.2 \\
$\left({ }^{\circ} \mathrm{C}\right)$ & 夏 & 7.6 & 7.6 & 6.9 & 6.9 & 7.4 & 8.4 \\
& 秋 & -2.0 & -3.4 & -1.7 & -3.3 & -2.7 & -2.0 \\
& 冬 & -13.6 & -12.9 & -12.4 & -13.6 & -12.7 & -11.2 \\
\hline
\end{tabular}

\section{2 全县湖泊变化}

从 MODIS 遥感资料对玛多县 2001-2006 年 5 月份和 9 月份的水体监测结果(图 2)可以看出, 全县的湖泊 面积从 2001-2006 年总体上是增加的, 且 5 月份的湖泊总面积小于 9 月份的湖泊面积(2006 年除外); 以 2003 年为界, 从 2001-2003 年全县湖泊面积逐年减少, 而从 2003-2006 年全县湖泊面积逐年增加, 以 2003 年为最 低值, 2006 年全县湖泊面积比 2001 年增加 $56.59 \mathrm{~km}^{2}$. 全县湖泊个数的变化与面积变化趋势基本一致, 也是以 2003 年为最低值, 2006 年湖泊比 2001 年多 35 个. 分析玛多县的气候资料(图 1)发现, 从 2001-2006年, 以 2003 年的年蒸发量为最大, 而 2003 年年降水量仅次于 2001 年, 年平均气温仅低于 2006 年, 气温的升高、降水量 的减少、蒸发量的增加可能是导致 2003 年湖泊面积达到极值的主要原因; 此外, 从 2003 年以来, 黄河源区先 后开始推行退牧还草和三江源生态保护工程，通过移民搬迁、禁牧封育、人工增雨和以草定畜等一系列工程 项目的实施 ${ }^{[8]}$, 黄河源区的生态逐步恢复, 使得曾经消失的湖泊逐渐重现, 河流湖泊水量逐渐增加. 
2006 年 5 月份的湖泊面积和个数大于 9 月份, 这可能是由于前年冬天的积雪融化所导致的. 2005 年 10 月下旬清水河流域(主要包括玛多和称 多两县)连续出现降雪天气过程, 期间气温偏低, 积雪融化缓慢，根据青海省遥感中心 EOS/MODIS 卫星遥感动态监测积雪发现, 玛多 县最大积雪面积达 $2.02 \times 10^{4} \mathrm{~km}^{2}$, 其中 $10 \mathrm{~cm}$ 以上 积雪占总积雪面积比例为 $68.58 \%-80.90 \%$, 构成 了特大雪灾, 直至 2006 年 3 月下旬至 4 月份, 随 着气温的升高, 积雪才开始迅速融化.

\section{3 主要湖泊变化}

玛多县主要湖泊有扎陵湖、鄂陵湖、冬给措纳 湖、尔拉拉湖、星星海 (包括阿涌贡玛错、阿涌哇 玛错、阿涌尔玛错) 等 (图 3). 扎陵湖、鄂陵湖为吞 吐湖, 是黄河源头两大主要湖泊, 习称姐妹湖, 对 黄河源头径流具有滞蓄、调节作用 ${ }^{[9]}$. 两湖湖水补 给源主要为河流、大气降水和积雪融水, 海拔约 $4300 \mathrm{~m}$, 据青海省三江源志记载鄂陵湖、扎陵湖的 面积分别为 $526.1 \mathrm{~km}^{2} 、 610.7 \mathrm{~km}^{2[10]}$; 冬给措纳湖、 尔拉拉湖、阿涌贡玛错、阿涌哇玛错、阿涌尔玛错 的海拔分别为 $4100 \mathrm{~m} 、 4438 \mathrm{~m} 、 4300 \mathrm{~m} 、 4300 \mathrm{~m}$ 、 $4250 \mathrm{~m}$ ，由 1988 年青海省测绘资料统计其面积分别 为 $231.27 \mathrm{~km}^{2} 、 22.74 \mathrm{~km}^{2} 、 25.87 \mathrm{~km}^{2} 、 35.63 \mathrm{~km}^{2}$ 、 $22.11 \mathrm{~km}^{2}$, 冬给措纳湖、不拉拉湖的补给主要为河流 和大气降水, 而星星海(包括阿涌贡玛错、阿涌哇玛 错、阿涌尔玛错)随着气温上升, 水位下降, 这几个湖 泊已成为内陆湖泊 ${ }^{[9]}$, 其补给源主要为大气降水.

近年来玛多县各主要湖泊 5 月份和 9 月份面 积的变化情况(表 2)可知, 各主要湖泊的变化趋势 不尽相同, 其中从 2001-2006 年鄂陵湖、扎陵湖面 积总体上是增加的, 5 月份与 9 月份总体变化趋势 是一致的, 但 5 月份的增幅大于 9 月份, 这可能是 由于春季气温明显升高, 使 5 月份的积雪融水增

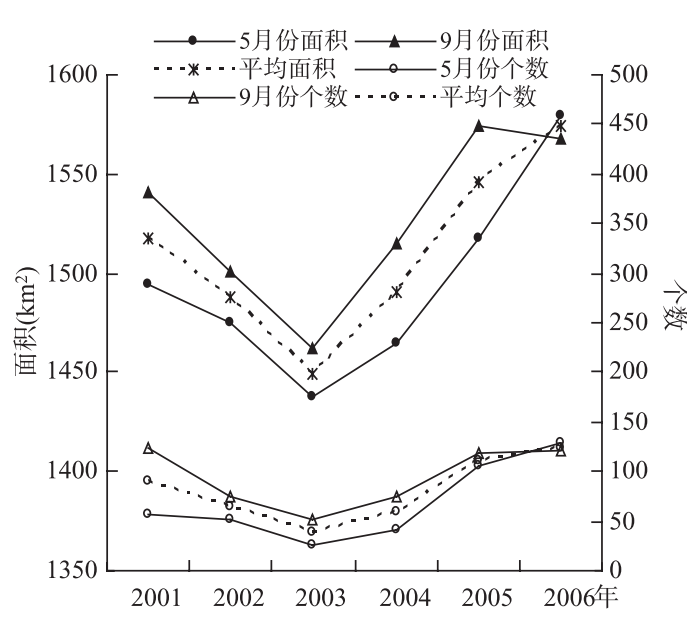

图 2 全县湖泊面积、个数变化

Fig.2 Changes of lake area and lake amount in Maduo County

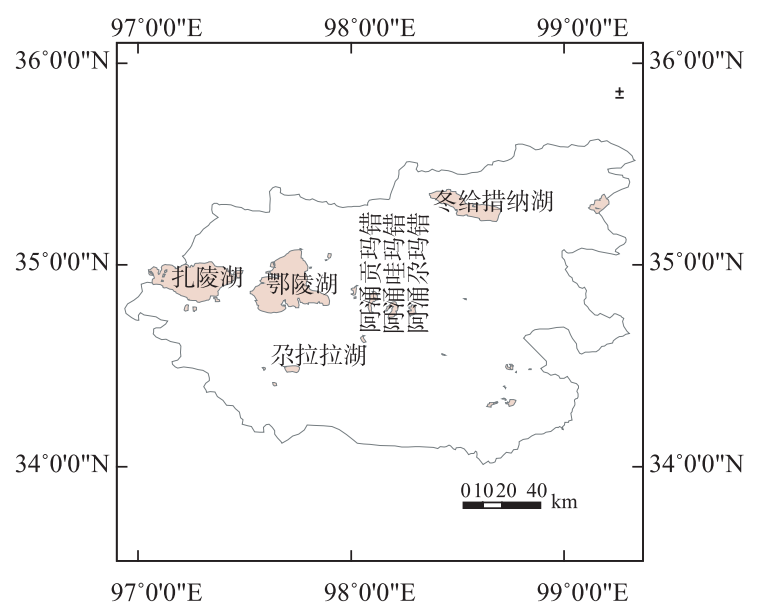

图 3 玛多县主要湖泊位置

Fig.3 The location of each main lake in Maduo County 多所致; 冬给措纳湖面积 5 月份和 9 月份波动都比较小, 总体上面积基本没有变, 尔拉拉湖 9 月份湖泊面积 波动较小且保持不变, 而 5 月份面积年际变化较大, 这是因为 5 月份尔拉拉湖湖面有部分积雪覆盖, 未能准 确提取其面积所致; 星星海(包括阿涌贡玛错、阿涌哇玛错、阿涌尔玛错) 5 月份和 9 月份的年际变化趋势不 一致, 且年际波动十分剧烈, 这可能是因为星星海湖盆较浅, 面积较小, 与大气降水多少密切相关所致.

\section{4 玛多县气候与湖泊变化的相关分析}

从表 3 可知, 各气候要素与湖泊面积的相关性均未达到显著水平, 这可能是因为所选取的年份太短的 缘故. 从全县的湖泊面积与各气候要素的相关系数可以看出, 年降水量与全县湖泊面积相关系数最大 (0.433), 说明年降水量对全县湖泊面积的影响较大. 而年平均气温对扎陵湖、鄂陵湖的影响较大, 其次是年 降水量、年蒸发量. 年降水量、年蒸发量与冬给措纳湖、尔拉拉湖的相关系数基本相当.

\section{5 讨论}

由上述分析得出玛多县的气候向暖湿化趋势发展, 冬季增温明显. 该县的湖泊面积从 2001-2006 年整 
体上是增加的, 2006 年全县湖泊面积比 2001 年增加 $56.59 \mathrm{~km}^{2}$; 以 2003 年为界, 从 2001-2003 年全县湖泊面 积逐年减少，而从2003-2006年全县湖泊面积逐年增加. 全县湖泊个数的变化与面积变化趋势基本一致，也 是以 2003 年为最低值, 2006 年湖泊个数比 2001 年增加 35 个. 各主要湖泊呈现不同的变化趋势, 与全县湖 泊的变化趋势不太一致. 由于选取的年份太短，各气候要素与湖泊面积的相关性均未达到显著水平，但总 体上年降水量与全县湖泊面积相关系数最大 $(0.433)$, 说明年降水量对全县湖泊面积的影响较大. 各主要湖 泊受各气候要素的影响大小也不一样. 由于受气象资料的限制, 玛多全县只有一个气象站, 如果增加气象 站点或进行气象资料的空间插值, 可能更能准确的分析影响湖泊变化的原因.

表 2 从 2001-2006 年玛多县各主要湖泊 5 月份和 9 月份面积 $\left(\mathrm{km}^{2}\right)$

Tab.2 Area of each main lake in May and September from 2001 to 2006 in Maduo County $\left(\mathrm{km}^{2}\right)$

\begin{tabular}{lllllllll}
\hline 年 & 月 & 扎陵湖 & 鄂陵湖 & \multicolumn{2}{l}{ 冬给措纳湖 尔拉拉湖 } & \multicolumn{3}{l}{ 阿涌贡玛错 阿涌哇玛错 阿涌尔玛错 } \\
\hline \multirow{2}{*}{2001} & 5 & 511 & 596.5 & 216.63 & 5.88 & 21.06 & 23.06 & 14.5 \\
& 9 & 503.75 & 605 & 221.94 & 19.44 & 23.06 & 25.19 & 12.81 \\
2002 & 5 & 498.25 & 602.88 & 218 & 1.31 & 20.19 & 23.25 & 9.88 \\
& 9 & 498.06 & 598.88 & 218.88 & 19 & 22.44 & 24.25 & 12.75 \\
2003 & 5 & 500 & 579.06 & 213.44 & 13.31 & 19.94 & 20.69 & 9.38 \\
& 9 & 493.25 & 578.5 & 213.81 & 19.63 & 21.25 & 21.81 & 10.38 \\
2004 & 5 & 500.5 & 576.63 & 214.44 & 19.69 & 22.44 & 22.69 & 9.81 \\
& 9 & 508.75 & 599.75 & 218.38 & 20.5 & 21.81 & 22.38 & 6.38 \\
2005 & 5 & 513.19 & 597.69 & 223.5 & 21.31 & 24.5 & 24 & 5.19 \\
& 9 & 511.94 & 602.38 & 221.25 & 20.75 & 21.56 & 22.5 & 12.38 \\
2006 & 5 & 543.75 & 624.38 & 224.81 & 1.30 & 23.94 & 23.44 & 13.56 \\
& 9 & 514.13 & 616.81 & 221.19 & 20.44 & 21.63 & 22.25 & 12.88 \\
\hline
\end{tabular}

表 3 玛多县主要湖泊面积与气候要素相关系数

Tab.3 Correlation coefficient between the main lakes' area and climatic elements

\begin{tabular}{llll}
\hline & 年降水量 & 年均气温 & 年蒸发量 \\
\hline 扎陵湖 & 0.334 & 0.511 & -0.086 \\
鄂陵湖 & 0.168 & 0.409 & -0.085 \\
冬给措纳湖 & 0.489 & 0.224 & -0.495 \\
尔拉拉湖 & 0.596 & -0.419 & -0.548 \\
全县湖泊 & 0.433 & 0.303 & -0.361 \\
\hline
\end{tabular}

\section{6 参考文献}

[1] 董立新, 王文科, 孔金玲等. 黄河上游玛多县生态环境变化遥感监测及成因分析. 水土保持通报, 2005, 25(4): 68-72.

[2] 鲁安新, 姚檀栋, 王丽红等. 青藏高原典型冰川和湖泊变化遥感研究. 冰川冻土, 2005, 27(6): 783-792.

[3] 李道峰, 刘昌明. 黄河河源区近 10 年来土地覆被变化研究. 北京师范大学学报(自然科学版), 2004, 40(2): 269-275.

[4] 王根绪, 丁永建, 王 建等. 近 15 年来长江黄河源区的土地覆被变化. 地理学报, 2004, 59(2): 163-173.

[5] 刘玉洁, 杨忠东主编. MODIS 遥感信息处理原理与算法. 北京: 科学出版社, 2001: 1-3.

[6] 梅安新, 彭望琭, 秦其明等编. 遥感导论. 北京: 高等教育出版社, 2002: 236-237.

[7] 杨兰芳. 应用 EOS/MODIS 资料监测河西内陆河下游水库湖泊水域的变化. 干旱气象, 2005, 23(1): 49-53.

[8] 杨寿德. 黄河源头地区生态系统开始恢复. 草业科学, 2006, 11: 95 .

[9] 李万寿, 冯 玲, 孙胜利. 扎陵湖、鄂陵湖对黄河源头年径流的影响. 地理学报, 2001, 56(1): 75-82.

[10] 韩 荣, 赵春香, 杜文忠等编. 青海省志. 长江黄河澜沧江源志. 郑州: 黄河水利出版社, 2000: 234-239. 